\title{
Insecurity and the Pattern of Trade: An Empirical Investigation
}

\author{
James E. Anderson \\ Boston College and NBER
}

\author{
Douglas Marcouiller \\ Boston College
}

\author{
Revision of NBER Working Paper \#7000
}

Revision date: 3 August 2000

JEL Codes: F1, D23, O17

Corruption and imperfect contract enforcement dramatically reduce international trade. This paper estimates the reduction using a structural model of import demand in which insecurity acts as a hidden tax on trade. We find that inadequate institutions constrain trade as much as tariffs do. We also find that omitting indexes of institutional quality biases typical gravity model estimates, obscuring a negative relationship between per capita income and the share of total expenditure devoted to traded goods. Finally, we argue that cross-country variation in the effectiveness of institutions and consequent variation in the prices of traded goods offer a simple explanation of the stylized fact that high-income, capital-abundant countries trade disproportionately with each other.

We thank many people for comments, especially Jeffrey Bergstrand, Donald Davis, Robert Feenstra, Gordon Hanson, David Hummels, two anonymous referees, and participants in seminars sponsored by Boston University, the University of Connecticut, Harvard University, the University of Notre Dame, the National Bureau of Economic Research, the Centre for Economic Policy Research, the Latin American and Caribbean Economics Association, and the Midwest International Economics Working Group. David Tarr and Francis Ng of the World Bank provided tariff data. Yuriy Tchamourliyski provided very able research assistance. 
Popular accounts of globalization skirt a provocative question: why is there so little international trade? Why is there less North-South trade than one would expect given differences in relative factor endowments? Why do international borders constrain exchange much more than can be explained by tariffs, quotas, and formal impediments to trade?

We contend that trade is reduced in response to hidden transactions costs associated with the insecurity of international exchange. Contracts may not be enforced. Bribes may be extorted. Shipments may be hijacked. Anecdotal evidence of insecurity is easy to find. Table 1, for example, shows the ranking in order of importance of "the obstacles for doing business" as reported in a 1996 World Bank survey of 3685 firms in 69 countries (Brunetti, Kisunko, and Weder, 1997). It is not surprising that firms complain about taxes; it is remarkable, however, that corruption ranks as the second most important obstacle to business worldwide, with crime and theft not far behind.

This paper develops a model of import demand in an insecure world. Our structural model is grounded in a multicountry generalization of the model of predation presented by Anderson and Marcouiller (1998); a similar structure can be derived from the model of incomplete contract enforcement in Anderson and Young (1999).

Fitting the structural model to the data, we show that trade expands dramatically when it is supported by strong institutions - specifically, by a legal system capable of enforcing commercial contracts and by transparent and impartial formulation and implementation of government economic policy. We estimate, for example, that if the indexes of institutional quality associated with the Latin American countries in our sample were to rise to the levels associated with the European Union, Latin American trade would expand by $30 \%$ on average, other things equal. This expansion is roughly equivalent to what we would expect from the reduction of Latin American tariffs to US levels.

Empirical work which ignores the security of exchange suffers from an important omitted variables bias. Our model shows that the share of expenditure devoted to traded goods falls as income per capita rises. When 
institutional variables are excluded from the regression, however, as in most of the existing gravity literature, trade shares are positively associated with income per capita. The bias is due to the positive correlation of income per capita and institutional quality.

The stylized fact that high-income, capital-abundant countries trade disproportionately with each other, rather than with low-income, laborabundant countries, has been used to motivate models of trade based on product differentiation rather than factor endowments. Insecurity provides a simple alternative explanation: good institutional support for trade among high-income countries lowers transactions costs, and the consequent price effects encourage these countries to trade disproportionately with one another. Note that our argument does not imply, counterfactually, that low-income countries should also trade disproportionately with each another.

Methodologically, this paper is closely related to the large gravity literature (Anderson 1979; Bergstrand 1985 and 1989; Thursby and Thursby 1987; Oguledo and MacPhee 1994; Gould 1994; McCallum 1995; Frankel, Stein and Wei 1998; Helliwell 1998; Feenstra, Markusen and Rose 1999; Baier and Bergstrand 1999). We estimate relative import demands to deal with a specification error suggested by Anderson's rationale for the gravity equation. We also suggest a way of dealing with the price index problem which arises in the gravity literature.

This paper tackles just one part of the problem of resistance to trade. We do not construct a political economic model capable of explaining the emergence of good institutions. We cannot add much to the discussion of the negative effect of distance on trade (Grossman 1998, but also see Hummels 1999); although it is possible that traversing great distances might increase exposure to misappropriation, our model cannot distinguish that effect from other distancerelated costs. We do not consider the role of networks in reducing information costs associated with international trade, although we find such models quite plausible (Casella and Rauch 1998, Rauch 1999, Rauch and Trindade 1999). Indeed, information-based models and ours overlap to the extent that information about exposure to misappropriation matters. 


\section{Import Demand in an Insecure World}

A simple observation underlies our work: international exchange is insecure. Shipments may be hijacked. Bribes may be extorted. Contracts may not be enforced.

Our hypothesis is that insecurity constrains trade by raising the price of traded goods. In an earlier paper we developed a model in which individuals freely allocate their labor across productive and predatory activities, endogenously determining the proportion of shipments which will be lost (Anderson and Marcouiller 1998). We now develop a model in which the probability of loss is reflected in a price mark-up equivalent to a hidden tax on trade. Analogously, Anderson and Young (1999) show that imperfect contract enforcement in the importer's country is equivalent under risk neutrality to a tariff.

Our model assumes two-stage budgeting. Agents first determine the proportion of total expenditure to allocate to internationally traded goods. In a second stage they allocate traded goods expenditure across goods. The firststage preferences are not restricted beyond quasi-concavity. Preferences across tradable goods are CES and identical across countries. Production is specialized so that each country produces one non-traded good and one traded good. Traded goods are differentiated by place of origin. ${ }^{1}$

Demand in country $i$ for the traded good produced in country $j$ is given by:

$$
m_{i j}=\alpha_{j}\left(\frac{p_{i j}}{P_{i}}\right)^{-\sigma} P_{i}^{-1} x_{i}
$$

where $x_{i}$ is country $i$ 's total expenditure on traded goods, $p_{i j}$ is the price of $j$ 's good in $i$ with producer prices $p_{j j}$ normalized to one ${ }^{2}, P_{i}=\left[\sum_{j} \alpha_{j} p_{i j}^{1-\sigma}\right]^{1 /(1-\sigma)}$ is the

\footnotetext{
${ }^{1}$ Helliwell 1998, p. 10, notes other papers using this Armington assumption.

${ }^{2}$ We assume here that domestic exchange is not subject to predation. This issue is addressed below and in the Appendix.
} 
CES price index for traded goods in $i$, and $\sigma$ is the elasticity of substitution among traded goods.

We eliminate the product-specific parameters $\alpha_{j}$ by working with imports by $i$ from $j$ relative to imports by $k$ from $j$ :

$$
\frac{m_{i j}}{m_{k j}}=\left(\frac{p_{i j}}{p_{k j}}\right)^{-\sigma}\left(\frac{P_{i}}{P_{k}}\right)^{\sigma-1} \frac{x_{i}}{x_{k}} .
$$

Working with relative demands addresses a specification error which plagues many empirical studies following Anderson's (1979) rationale for the gravity equation. The gravity model is derived from the import demand system by imposing the adding up constraint that shipments to the entire world be equal to income, then solving the constraint for the expenditure share for each exporter, and finally substituting this exporter-specific expenditure share into the import demand equation. Following this logic, the correct specification of the gravity equation includes a highly nonlinear exporter-specific price index on the right hand side. Focusing on imports by $i$ and $k$ from the same exporter $j$ eliminates this complication, although the importer-specific price index remains.

The price of $j$ 's product in $i$ exceeds the producer's price due to an "insecurity" markup, a transport cost, and a tariff if applicable. The deployment of a good deal of algebraic artillery ${ }^{3}$ (see Appendix A) leads to the simple and plausible result that the magnitude of the insecurity markup depends on the quality of a country's institutions for the defense of trade and on factors which allow traders to use those institutions skillfully. This leads us to postulate the following relation between the price of country $j$ 's export in country $i$ and its price in country $k$ :

$$
\frac{p_{i j}}{p_{k j}}=\left(\frac{S_{i}}{S_{k}}\right)^{\delta 1}\left(\frac{1+b_{i j}}{1+b_{k j}}\right)^{\delta 2}\left(\frac{1+l_{i j}}{1+l_{k j}}\right)^{\delta 3}\left(\frac{d_{i j}}{d_{k j}}\right)^{\delta 4}\left(\frac{1+\left(1-a_{i j}\right) t_{i}}{1+\left(1-a_{k j}\right) t_{k}}\right) .
$$

In this equation, $S_{i}$ denotes the strength of the importing country's institutions for defending trade. Indicator variables $b_{i j}$ and $l_{i j}$ take the value 1 if the importer and exporter share a common border or a common language, both of which

\footnotetext{
${ }^{3}$ We thank a referee for this image.
} 
encourage familiarity and may enhance the exporter's skill in using the institutions of the importing country for the defense of his or her shipments. Increasing the distance between the trading partners, $d_{i j}$, increases transport costs and may also expose goods to greater risk of misappropriation during shipment. The variable $t_{i}$ is the importer's average ad valorem tariff rate, and $a_{i}$ is an indicator which takes the value 1 if the partners are associated in a free trade agreement (so that the tariff is not applied by country $i$ to imports from country $j$ ). The tariff term lacks an exponent because an ad valorem tariff raises the price precisely in proportion to the tariff.

The model we present here is for simplicity one of insecurity in international trade. Difficulties in contract enforcement are most acute where multiple legal jurisdictions are involved (Rodrik, 2000). Moreover, actors within a single economy are likely to have easier access to the sort of informal enforcement mechanisms assumed in Marcouiller and Young (1995). Appendix A formalizes our model and shows that the extension to allow predation on domestic exchange is of little consequence to the interpretation of our results. Equation 1.2 can be reinterpreted to extend to cases in which an insecurity markup also applies to domestic purchases of the exportable good. If we normalize to one the price of $j$ 's tradable good at the factory door, its price to consumers in the home country, $p_{j j}$, would be affected by institutional quality just as suggested by Equation 1.2 (see Appendix A for the details of this argument).

A country's total expenditure on traded goods, $x_{i}$, is some fraction $\phi$ of its total income. We model the share of total expenditure devoted to traded goods as a reduced form function reflecting the interplay of demand and supply in general equilibrium. In the cross section, appropriate exogenous variables include the country's total income, its income per capita, and its traded goods price index. The equilibrium price of the non-traded good is a reduced form function in the same variables and is subsumed in the traded goods expenditure 
share function. ${ }^{4}$ A variety of static structural models yield such a function. ${ }^{5}$ Anderson (1979) rationalized this reduced form with a model of perfect competition and constant returns to scale. ${ }^{6}$ Bergstrand $(1985,1989)$ developed the reduced form from a model with monopolistic competition and economies of scale. Income and income per capita pick up the effect of factor endowments, possibly nonhomothetic preferences, and possible scale economies, while the traded goods price index picks up substitution between traded and non-traded goods. (Of course, the reduced form parameters are combinations of the various structural elasticities in supply and demand.) Imposing log linearity, we postulate as the reduced form traded goods expenditure share:

$$
\phi\left(y_{i}, n_{i}, P_{i}\right)=\lambda y_{i}^{\gamma 1}\left(y_{i} / n_{i}\right)^{\gamma 2}\left(P_{i}\right)^{\gamma 3}
$$

where $y_{i}$ is national income and $n_{i}$ is population. Then:

$$
\frac{x_{i}}{x_{k}}=\frac{y_{i}^{(1+\gamma 1)}\left(y_{i} / n_{i}\right)^{\gamma 2} P_{i}^{\gamma 3}}{y_{k}^{(1+\gamma 1)}\left(y_{k} / n_{k}\right)^{\gamma 2} P_{k}^{\gamma 3}} \text {. }
$$

Note the double role played in our model by the traded goods price index, $P_{i}$, which affects relative imports both through the CES demand functions and through the traded goods expenditure share.

${ }^{4}$ We suppress here for simplicity any effect of insecurity on the equilibrium price of the non-traded good. See the Appendix for a demonstration that this is a harmless simplification.

${ }^{5}$ Our empirical work explains trade in a single year, so static models are appropriate. In reality, balanced trade is rare and the traded goods expenditure share reflects an intertemporal margin of decision-making. We ignore this margin because it is remote from the concerns of our model and seems unlikely to add to its explanatory power. Temporary trade control measures taken for balance of payments reasons will show up in the traded goods price index. ${ }^{6}$ Let $e(h, p, u)$ be the expenditure function of the representative agent and let $g(h, 1, v)$ be the gross domestic product function. We have set export prices in equilibrium at unity, with landed import prices equal to the vector $p>1$ due to transactions costs. The non-traded "home" good price is $h$, while the vector of factor endowments is $v$. Equilibrium is defined by the values of utility and nontraded goods prices consistent with balanced trade and home market clearance: $\{U(p, v), H(p, v)\}=\left\{u, h \mid e(h, p, u)-g(h, 1, v)=0, e_{h}(h, p, u)-g_{h}(h, 1, v)=0\right\}$. We use Shephard's and Hotelling's lemmas in defining market clearance. The reduced form traded goods expenditure share is defined as $\phi(p, v) \equiv 1-H(p, v) e_{h}[H(p, v), p, U(p, v)] / e[\cdot]$. We further simplify by using a CES aggregator of traded goods prices $P(p)$. 
We approximate the relative traded goods price index by a version of the Törnqvist index:

$$
\ln \left(\frac{P_{i}}{P_{k}}\right)=\sum_{j} w_{j} \ln \left(\frac{p_{i j}}{p_{k j}}\right)
$$

where $w_{j}$ represents the ratio of expenditure on traded good $j$ (produced by exporting country $j$ under our assumptions about specialization) to total expenditure on all traded goods including the tradable good produced at home. It can be shown that for a given consuming country $i$ :

$$
w_{i j}=\frac{p_{i j} m_{i j}}{\sum_{j, j \neq i} p_{i j} m_{i j}}\left(1-w_{i i}\right) .
$$

We use this to construct a set of weights $w_{j}$ which sum to one and which are identical across consumers. Ignoring this importer-specific price index, as the gravity literature sometimes has, certainly results in misspecification. Our approximation is an imperfect but sensible and operational measure. ${ }^{8}$

This approach to the price index implies a "remoteness" index like that often justified on intuitive grounds, since $\sum_{j} w_{j} \ln \left(d_{i j} / d_{k j}\right)$ is an element of $\sum_{j} w_{j} \ln \left(p_{i j} / p_{k j}\right)$. (Different authors have used different weights, none resembling ours and none with a base in theory.) Analogous intuitions can be offered for other terms of the price index. For example, bilateral trade is expected to be greater when the partners speak a common language than when they do not. However, the effect on bilateral trade might well be greater for two countries which speak Dutch, a relatively uncommon language, than for two English-speaking countries with many potential same-language partners. Since $\sum_{j} w_{j} \ln \left(\left(1+l_{i j}\right) /\left(1+l_{k j}\right)\right)$ is an element of $\sum_{j} w_{j} \ln \left(p_{i j} / p_{k j}\right)$, our treatment of the price index ought to pick up any such second-order effect. While we do not discount intuition, we note that the strength of our approach is that we are able to define appropriate weights and a common treatment of the set of such effects.

${ }^{7}$ Oguledo and MacPhee (1994) follow Bergstrand.

${ }^{8}$ The previously cited papers by Bergstrand and by Gould also address this issue. 
Substituting (1.2) and (1.4) into (1.1) and taking logs:

$$
\begin{aligned}
\ln \frac{m_{i j}}{m_{k j}}= & \left(1+\gamma_{1}\right) \ln \left(\frac{y_{i}}{y_{k}}\right)+\gamma_{2} \ln \left(\frac{y_{i} / n_{i}}{y_{k} / n_{k}}\right)+\left(\sigma-1+\gamma_{3}\right) \ln \left(\frac{P_{i}}{P_{k}}\right)-\sigma \delta_{1} \ln \left(\frac{S_{i}}{S_{k}}\right) \\
& -\sigma \delta_{2} \ln \left(\frac{1+b_{i j}}{1+b_{k j}}\right)-\sigma \delta_{3} \ln \left(\frac{1+l_{i j}}{1+l_{k j}}\right)-\sigma \delta_{4} \ln \left(\frac{d_{i j}}{d_{k j}}\right)-\sigma \ln \left(\frac{1+\left(1-a_{i j}\right) t_{i}}{1+\left(1-a_{k j}\right) t_{k}}\right) .
\end{aligned}
$$

Using (1.5) and (1.2) again:

$$
\begin{aligned}
\ln \left(\frac{P_{i}}{P_{k}}\right)= & \delta_{1} \sum_{j} w_{j} \ln \left(\frac{S_{i}}{S_{k}}\right)+\delta_{2} \sum_{j} w_{j} \ln \left(\frac{1+b_{i j}}{1+b_{k j}}\right)+\delta_{3} \sum_{j} w_{j} \ln \left(\frac{1+l_{i j}}{1+l_{k j}}\right) \\
& +\delta_{4} \sum_{j} w_{j} \ln \left(\frac{d_{i j}}{d_{k j}}\right)+\sum_{j} w_{j}\left(\frac{1+\left(1-a_{i j}\right) t_{i}}{1+\left(1-a_{k j}\right) t_{k}}\right) .
\end{aligned}
$$

Two simplifications come into play when we substitute (1.7) into (1.6). The ratio $S_{i} / S_{k}$ does not vary across exporters $j$. Therefore,

$$
\sum_{j} w_{j} \ln \left(\frac{S_{i}}{S_{k}}\right)=\ln \left(\frac{S_{i}}{S_{k}}\right) \text {. }
$$

Similarly, since relatively few of our bilateral trade flows involve free trade agreements which cause average tariffs to vary across exporters, we also collapse the "weighted sum" of the relative tariffs into the original tariff term. This leaves us with the following model of imports by country $i$ from $j$ relative to imports by the base country $k$ from the same exporter $j$ :

$$
\begin{aligned}
\ln \frac{m_{i j}}{m_{k j}}= & \left(1+\gamma_{1}\right) \ln \left(\frac{y_{i}}{y_{k}}\right)+\gamma_{2} \ln \left(\frac{y_{i} / n_{i}}{y_{k} / n_{k}}\right)+\left(\gamma_{3}-1\right) \delta_{1} \ln \left(\frac{S_{i}}{S_{k}}\right)-\sigma \delta_{2} \ln \left(\frac{1+b_{i j}}{1+b_{k j}}\right) \\
& -\sigma \delta_{3} \ln \left(\frac{1+l_{i j}}{1+l_{k j}}\right)-\sigma \delta_{4} \ln \left(\frac{d_{i j}}{d_{k j}}\right)+\left(\gamma_{3}-1\right) \ln \left(\frac{1+\left(1-a_{i j}\right) t_{i}}{1+\left(1-a_{k j}\right) t_{k}}\right) \\
& +\left(\gamma_{3}-1+\sigma\right)\left[\delta_{2} \sum_{j} w_{j} \ln \left(\frac{1+b_{i j}}{1+b_{k j}}\right)+\delta_{3} \sum_{j} w_{j} \ln \left(\frac{1+l_{i j}}{1+l_{k j}}\right)+\delta_{4} \sum_{j} w_{j} \ln \left(\frac{d_{i j}}{d_{k j}}\right)\right]
\end{aligned}
$$

Note that the variable of primary interest to us, security, potentially affects prices and relative imports through three channels: the substitution effect within the group of traded goods $\left(p_{i j} / P_{i}\right)^{-\sigma}$, the general equilibrium substitution effect between traded and non-traded goods $\partial \phi / \partial P_{i}$, and the real income effect, $\partial\left(x_{i} / P_{i}\right) / \partial P_{i}$. Country $i$ 's security, $S_{i}$, does not affect the relative prices it faces 
within the set of traded goods, $p_{i j} / P_{i}$, so the first of the substitution effects is nil. The reduced form coefficient on the institutional quality index, $\left(\gamma_{3}-1\right) \delta_{1}$, is the product of $\delta_{1}$, which captures the elasticity of the price index $P_{i}$ with respect to $S_{i}$ , and $\gamma_{3}-1$, which captures the net elasticity of trade with respect to $P_{i}$. The term $\gamma_{3}-1$ is itself the sum of the real income elasticity, -1 , and the general equilibrium substitution elasticity, $\gamma_{3}$ in Equation 1.4. ${ }^{9}$

All the major elements of our model are now in place. We have modeled a world in which traded goods are differentiated by place of origin. Differences across importers in demand for a single good have three sources: (a) differences in the price markups associated with insecurity, distance, and tariffs, (b) differences in total expenditure, and (c) differences in the division of expenditure between traded and non-traded goods.

\section{Data}

The security of exchange depends on the strength of the institutions which support transactions among private firms and transactions between the private sector and the state. We rely on data provided by the World Economic Forum (WEF) to measure the quality of both sets of institutions. The measures are drawn from the WEF 1997 Executive Survey, which was completed by more than 3000 participants distributed across 58 countries (World Economic Forum 1997, p.85). Participants in the WEF survey were asked to assign a score ranging from one (strongly disagree) to seven (strongly agree) to each of the following statements:

- Government economic policies are impartial and transparent;

- The legal system in your country is effective in enforcing commercial contracts.

We rescale the mean response for each country to run from zero to one. Figure 1

${ }^{9}$ The Appendix shows that a reduced form coefficient for the institutional index with a more complex interpretation emerges from a model in which domestic exchange is also insecure. Nothing in what follows hangs on the particular "structural" interpretation of the institutional index coefficient. 
plots each country's score on "enforceability" against its score on "transparency."

Admittedly, these are noisy signals of institutional strength. Expectations differ across countries, so that what counts as "effective" enforcement or "impartial" policy in the Ukraine may differ from what would be similarly classified in Singapore. The respondents to the survey form a selected group even if they were randomly selected within a country, they would still represent only those who had chosen not to relocate or to shut down. Moreover, the Forum provides only the mean response for each country; we lack information about within-country variation in responses.

As a check on the robustness of our results, we also use a complementary "composite security" index formed from answers to the following eleven questions:

- Government economic policies are impartial and transparent;

- Government regulations are precise and fully enforced;

- Tax evasion is minimal;

- Irregular additional payments are not common in business and official transactions;

- The legal system is effective in enforcing commercial contracts ;

- Agreements and contracts with the government are not often modified due to budget cutbacks, changes in government or changes in government priorities;

- Private businesses can readily file lawsuits at independent and impartial courts if there is a breach of trust on the part of the government;

- New governments in your country honor the commitments and obligations of previous regimes;

- Citizens of your country are willing to adjudicate disputes rather than depending on physical force or illegal means;

- Your country's police are effective in safeguarding personal security so that this is not an important consideration in business activity;

- Organized crime does not impose significant costs on business in your 
country.

Respondents were asked to rank agreement with the statement on a scale from one to seven. We took the country mean responses to the eleven questions, rescaled them to run from zero to one, took logs, and then used factor analysis to extract the first principal factor, relying on the correlation matrix to uncover communality. Unrotated factor loadings were positive and of roughly similar magnitudes for each of the underlying variables. Commonality was high, uniqueness low, and we believe that the factor we have estimated on the basis of these eleven questions constitutes a meaningful composite security index. (The index has the further advantage of being independent of the selection of the base country $k$.) Table 2 shows the composite security score for each of the countries. $^{10}$

It has been suggested that our indexes of institutional quality may act as proxies for traditional barriers to trade. However, tariff barriers and trade preferences enter our model explicitly, and the correlation between institutional measures and nontariff barrier coverage ratios is low for those countries for which we have data. The correlation coefficient between the NTB coverage ratio and our index of transparency is -.32 , the correlation with our index of enforceability is -.14, and the correlation with our composite security index is .15. ${ }^{11}$ The signs are those which one might expect from a political economy perspective, but the magnitudes of the correlations are small.

Our data on 1996 bilateral import expenditures are taken from the IMF's Direction of Trade Statistics. Most of the DOTS import data are reported c.i.f., although some appear only f.o.b. To avoid as much as possible ad hoc adjustments to the data, we generally use the reported c.i.f. figures, adjusting the few f.o.b. figures upward by a factor based on the ratio between the country's

10 Scoring a new variable using the loadings for the first principal factor generates a variable with mean zero and standard deviation one. One can't take the log of such a variable. Instead, we have taken the logs of the mean responses to the eleven questions before extracting the first principal factor and scoring the new variable. Since the factor extraction is based on the correlation matrix, the composite indicator is invariant to the choice of base country $k$. 
total reported c.i.f. imports from the rest of the world and the world's reported exports to that country. ${ }^{12}$

Data on 1996 population and GDP in current dollars are taken from the World Bank's World Development Indicators (WDI). We calculate distance from capital city to capital city on the basis of geographical coordinates listed in Fitzpatrick and Modlin (1986); of course, the distance from Washington to Ottawa only roughly captures the average distance traversed by shipments from the United States to Canada. David Tarr and Francis Ng of the World Bank graciously provided us with unweighted average external tariff data; this series is far more complete than the data on import duties as a percentage of import expenditures reported in the WDI. ${ }^{13}$ We composed dummy variables to capture sharing a common border, a common language, or common membership in ASEAN, the EU, MERCOSUR, or NAFTA.

We have complete data on these variables for a total of 2182 import flows distributed across 48 importing countries. For an additional 24 bilateral pairs, no imports were reported. ${ }^{14}$ Table 3 shows the importing countries in our data set and the number of positive import flows which we observe for each.

\section{Estimation and Results}

Our structural model leads to a simple result. Relative import demand is a function of the relative levels of income, income per capita, institutional quality, a shared border, a shared language, distance, tariffs if applicable, and the overall traded goods price index. Estimation of the model supports three contentions: (a) by lowering transactions costs, institutional support for secure exchange

${ }^{11}$ The nontariff barrier coverage ratios are taken from the WEF's Global Competitiveness Report 1997, p.223. They are available for only 37 of our 48 countries.

${ }^{12}$ Estimates of our model over interpolated f.o.b. import flows, applying analogous factors of adjustment to deflate the c.i.f. import values to approximate f.o.b. equivalents, are available on request.

${ }^{13}$ Even so, not every country has data available for 1996. We have used 1996 data where available, but in other years have used tariff data from 1997, 1995, or 1994. 
significantly raises international trade volume;

(b) excluding institutional variables obscures a negative relation between income per capita and the share of income spent on traded goods;

(c) institutional differences can generate "a disproportionately high volume of trade among high-income countries," a pattern "which happens to accord well with trade patterns in the real world" (Deardorff 1998, p.16).

We begin by estimating Equation 3.1, a stochastic form of the model we developed in Section 1 (Equation 1.8):

$$
\begin{aligned}
\ln \frac{m_{i j}}{m_{k j}}= & \beta_{0}+\beta_{1} \ln \left(\frac{y_{i}}{y_{k}}\right)+\beta_{2} \ln \left(\frac{y_{i} / n_{i}}{y_{k} / n_{k}}\right)+\beta_{3} \ln \left(\frac{S_{i}}{S_{k}}\right) \\
& +\beta_{4} \ln \left(\frac{1+b_{i j}}{1+b_{k j}}\right)+\beta_{5} \ln \left(\frac{1+l_{i j}}{1+l_{k j}}\right)+\beta_{6} \ln \left(\frac{d_{i j}}{d_{k j}}\right)+\beta_{7} \ln \left(\frac{1+\left(1-a_{i j}\right) t_{i}}{1+\left(1-a_{k j}\right) t_{k}}\right) \\
& +\beta_{8} \sum_{j} w_{j} \ln \left(\frac{1+b_{i j}}{1+b_{k j}}\right)+\beta_{9} \sum_{j} w_{j} \ln \left(\frac{1+l_{i j}}{1+l_{k j}}\right)+\beta_{10} \sum_{j} w_{j} \ln \left(\frac{d_{i j}}{d_{k j}}\right)+v_{i}+\varepsilon_{i j}
\end{aligned}
$$

The stochastic term includes two elements. The first, $v_{i}$, captures any disturbance which systematically affects all of country $i$ 's imports relative to those of the base country $k$, recognizing the panel character of our data. The second element is specific to imports by $i$ from $j, \varepsilon_{i j}$. The base country $k$ is held constant. We estimate the model using Stata's White correction for possible heteroskedasticity, with clustering by importer. The standard errors estimated with clustering are approximately twice those derived from a simple White correction, indicating significant positive correlation of residuals within clusters.

Table 4 reports summary statistics for the import, GDP, GDP per capita, transparency, enforceability, composite security, common border, common language, distance and tariff ratios, as defined above, using the USA as a convenient base country $k$. Robustness of the results with respect to the choice of the base is explored below.

Table 5 reports the results of estimating Equation 3.1 under various restrictions. The last two columns show estimates from tobit models, with the

${ }^{14}$ That is, the country pair appears in the DOTS data matrix but the trade volume is given as "." There are a few other cases in which the country pair simply does not appear in the DOTS data. 
twenty-four unreported import flows taken to be zero (and left-censored) ${ }^{15}$ All six columns show robust standard errors with clustering by importer.

The first of our conclusions is that by lowering transactions costs, institutional support for secure exchange significantly increases trade. The composite security index has a positive and highly significant impact on imports (Reg 4). The transparency and enforceability indexes have independent positive effects (Reg 3), highly significant in the case of transparency and marginally so in the case of enforceability.

A few examples shed light on the magnitude of the effects implied by the point estimates. Transparency is rated roughly 10\% higher in France than in Argentina. Interpreting the estimated coefficient on transparency as a reduced form elasticity, this difference implies roughly $5 \%$ higher imports into France than into Argentina, other things equal.

If the seven Latin American countries in our sample (Argentina, Brazil, Chile, Colombia, Mexico, Peru, and Venezuela) were to enjoy the same transparency and enforceability scores as the mean ratings of the members of the European Union, predicted Latin American import volumes would rise 30\%. ${ }^{16}$ This increase is of roughly the same magnitude as the $35 \%$ increase which could be expected from lowering Latin American tariffs to the levels applied by the United States, holding other things equal. A much larger (51\%) increase in average Latin American GDP would be necessary to generate a comparable increase in imports.

As can be seen from Equation 1.8, these "thought experiments" involve several distinct effects. The calculations multiply the effect of insecurity on the

${ }^{15}$ With an elasticity of substitution among traded goods which exceeds one, high transactions costs can eliminate trade in some bilateral pairings. In this case, the $\log$ of the import ratio, $\ln (0)$, was assigned a value 0.1 below the log of the lowest positive import ratio in the data set.

${ }^{16}$ In response to the improvement in the transparency score, the log of relative imports would be expected to rise by .095, the product of the regression coefficient, .530, times the increase in $\log$ transparency from $\ln (0.99)$ to $\ln (1.19)$. The increase in $\log$ enforceability from $\ln (.62)$ to $\ln (.98)$ times its regression coefficient, .385 , would raise the log of relative imports by .174 . Exponentiating, the total increase of .269 in log imports is equivalent to multiplying import levels 
price markup $\left(\delta_{1}\right)$ by (i) the reduced form substitution effect on the division of expenditure between traded goods and the non-traded good $\left(\gamma_{3}\right)$, and (ii) the real income effect of the price change (-1). In the notation of Section 1 , the net effect of the security term is $\left(\gamma_{3}-1\right) \delta_{1}$.

The coefficient on the tariff variable in Table 5 represents an estimate of $\left(\gamma_{3}-1\right)$. When the institutional variables are included, we estimate the reduced form elasticity of import demand with respect to tariffs as roughly -4.8 , an estimate remarkably similar to the elasticity estimated by Baier and Bergstrand (1999). The estimate of $\hat{\gamma}_{3}=-3.8$ suggests that the substitution effect of insecurity on the trade share outweighs the real income effect, which is equal to -1 .

Comparison of Equations 1.8 and 3.1 implies that $\hat{\beta}_{4} / \hat{\beta}_{8}, \hat{\beta}_{5} / \hat{\beta}_{9}$, and $\hat{\beta}_{5} / \hat{\beta}_{10}$ should all be equal. F-tests on the estimated coefficients for the full model (Reg 3 and Reg 4) do not reject that hypothesis. ${ }^{17}$ Note that the positive sign on the weighted distance variable makes sense in terms of our model if the elasticity of substitution among traded goods is high. Assuming that $p_{i j}$ rises with the distance between $i$ and $j$, we expect $\delta_{4}$ to be positive. The positive estimated coefficient on the weighted distance term then requires that $\gamma_{3}+\sigma-1>0$. Using the estimate of $\hat{\gamma}_{3}=-3.8$ from the estimated coefficient on the tariff ratio gives us a lower bound on the elasticity of substitution among traded goods: $\sigma$ must be above 4.8 .

One can push the structural interpretation of the coefficients to its limit by estimating Equation 1.8 directly using maximum likelihood techniques. The estimated parameters and the associated robust standard errors (with clustering by importer, as always) are displayed in Table 6 . As expected, the estimated elasticity of substitution among the traded goods, $\hat{\sigma}$, is high. Higher security

by 1.30 , which we interpret as a rise of $30 \%$. A similar procedure underlies the other comparative statics calculations.

${ }^{17}$ Using Reg 3, the F-statistic for the joint hypothesis that $\hat{\beta}_{4} / \hat{\beta}_{8}=\hat{\beta}_{6} / \hat{\beta}_{10}$ and $\hat{\beta}_{5} / \hat{\beta}_{9}=\hat{\beta}_{6} / \hat{\beta}_{10}$ is $F(2,47)=1.08$. Using Reg 4 , the statistic is $F(2,47)=1.90$. 
lowers the price $p_{i j}$, as captured by the parameters $\hat{\delta}_{1 a}$ and $\hat{\delta}_{1 b}$ when transparency and enforceability are used and by $\hat{\delta}_{1}$ when the composite security score is used. By lowering $p_{i j}$ for all $j$, enhanced security also lowers $P_{i}$, with a positive effect on the traded goods expenditure share (through $\hat{\gamma}_{3}$ ). We do not wish to emphasize these maximum likelihood results, however, because they come from a model which is very highly constrained. The unconstrained regression results of Table 5 lead us to question the empirical importance of the weighted language and border variables, to which the constrained maximum likelihood model gives a good deal of influence as it forces the cross-term parameter restrictions to be met.

Our second major proposition is that higher income per capita reduces the share of expenditure devoted to traded goods, all else equal. Wealth is antitrade biased. The estimated coefficients on the log of per capita GDP in Table 5 are our estimates of $\gamma_{2}$, the reduced form elasticity of the traded goods expenditure share with respect to income per capita. As shown in Table 5, the estimates of this elasticity change sign as tariff and security variables are added to the regression. Inappropriate exclusion of the tariff and security variables leads to the result shown in the first column, with a "significantly" positive coefficient on GDP per capita. ${ }^{18}$ The coefficient becomes insignificantly different from zero when the tariff term is added. Including enforceability and transparency drives the coefficient into the negative range. Other things equal, doubling per capita income reduces the share of total expenditure devoted to traded goods by $20 \%$.

Our anti-trade bias result, which bears a resemblance to earlier work by Hunter and Markusen (1988), is what one expects if the proportion of expenditure devoted to non-traded services rises as income per capita rises. ${ }^{19}$ Our result stands in contrast to recent work which has found expenditure shares

${ }^{18}$ Of course, it is our contention that Reg 1 suffers from omitted variables bias. ${ }^{19}$ The reduced form permits no structural interpretation. A natural candidate is departures from homotheticity, but our result can be found in a model with homothetic preferences and constant returns technology. Future work should try to dig deeper into the structural basis of our reduced form result. 
to be invariant to income (Davis, Weinstein, Bradford and Shimpo, 1997, pp. 433436). It stands in even sharper contrast to work which finds a positive effect of income per capita on trade (Frankel, Stein and Wei 1998, p.96), an effect which we reproduce only by excluding the tariff and insecurity variables.

Econometrically, these changes in sign are driven by correlation between GDP per capita and the omitted variables. The correlation coefficient between GDP per capita and the tariff ratio is -.62 . When the tariff ratio is dropped from the regression, part of the positive effect of lower tariffs on trade is misread as a positive effect of higher income per capita on trade. The correlation between GDP per capita and the enforceability ratio is .55, and its correlation with the transparency ratio is $.73 .{ }^{20}$ When the tariff and institutional variables are dropped from the regression, part of the positive effect of security on trade is misattributed to income per capita. Including the theoretically appropriate regressors reveals that GDP per capita actually has a negative effect. Although the effect is imprecisely estimated, other things equal, a rise in income per capita seems likely to lower the share of a country's total income which is spent on traded goods. ${ }^{21}$

Of course, to the extent that countries with higher income per capita also enjoy better institutions for the defense of trade, the trade-restricting effect of income per capita could be offset by the trade-enhancing effect of lower traded goods prices. This combination of income and price effects explains why the data show a small positive correlation (.13) between per capita GDP and total imports divided by GDP. ${ }^{22}$

Our third main contention is that institutional differences can generate "a disproportionately high volume of trade among high-income countries," a

${ }^{20}$ This correlation is given in the data, but it does not imply that income per capita and institutional quality are necessarily linked, nor does it invalidate the "thought experiment" reported above in which institutions were improved without a corresponding increase in income per capita.

${ }^{21}$ In contrast, the anti-trade bias effect of size, the negative effect on trade shares of country size, measured by GDP, is unaffected by inclusion of security variables. Size is only weakly correlated with security.

${ }^{22}$ Note that the ratio of imports to GDP is not an exact measure of the traded goods expenditure share. It excludes expenditure on the domestically produced tradable good and includes expenditure on goods which are re-exported. 
pattern "which happens to accord well with trade patterns in the real world" (Deardorff 1998, p.16). Why should high-income countries skew their trade toward imports from other high-income countries - in spite of the presumed similarity of factor endowment? And what answer to the first question can be consistent with the stylized fact that low-income countries do not rely disproportionately on imports from other low-income countries?

Several solutions to the puzzle have been proposed (notably Markusen 1986). We offer an explanation based on the price markup associated with insecure trade. Effective institutions in the importing country lower transactions costs, lower the prices of traded goods, and raise imports, holding constant the characteristics of the exporting country. The predation model argues that the complete price markup also depends on the quality of institutions in the exporting country. Our empirical results confirm that low security in country $i$ lowers $m_{i j} / m_{k j}$; the predation model also implies that both $m_{i j}$ and $m_{k j}$ are low when the security of country $j$ is low. We cannot estimate this second effect, because the impact of the exporter's security and of the expenditure share $\alpha_{j}$ are not separately identified. The prediction of the model, however, clearly coincides with the observed pattern of trade. Trade among high-income countries with high-quality institutions ought to be high because the transactions costs associated with insecurity are low; transactions costs impose a double disadvantage on trade among low-income, low-security countries. This solves a problem alluded to in Deardorff's $(1998$, p.16) informal exposition of an explanation based on identical but non-homothetic preferences. Our story implies disproportionate trade among consumers of the "high-income" good, but it does not imply counterfactually a similarly disproportionate amount of trade among low-income consumers.

\section{Robustness}

The choice of the base country ought to make no difference to our results. However, in practice, two problems arise. We have no data on a country's consumption of its own tradable good, nor can that consumption be inferred 
from an adding up constraint since our model allows for a non-tradable good. Having no way to infer country $k^{\prime}$ s consumption of its own exportable, we cannot use the data we have on any country $i$ 's consumption of $k$ 's export. In other words, lacking data for $m_{k k}$, we lack the dependent variable $\ln \left(m_{i k} / m_{k k}\right)$ for the 47 other importers $i$, as well. Changing base country will change the set of 47 unusable observations, possibly affecting the results. Moreover, many of our independent variables take the form $\ln \left(x_{i} / x_{k}\right)$. The measurement error associated with $x_{k}$ depends on the choice of $k$, so the parameter estimates may vary with the choice of the base country. ${ }^{23}$ To test the importance of these effects, we reestimated the model using Brazil and China as alternative base countries. We found quite similar results. ${ }^{24}$

We have been asked whether our results are robust to the exclusion of all observations involving the United States as importer or exporter, testing the possibility that peculiarities of this very large economy may drive our results. Excluding all trade involving the United States, using Brazil and China as base countries, and recalculating appropriately the Törnqvist weights, generates results shown in Table 7 . The security effects are noticeably stronger here than in our base case. This is particularly true of the effect of contract enforceability.

A different problem occurs if the covariance of GDP and $v_{i}$ is not zero. If a single shock can simultaneously shift both the GDP of country $i$ and country $i$ 's imports from every country $j$, then our parameter estimates may be biased. Selecting instruments for GDP is quite difficult. However, in our cross-sectional context, one reasonable approach to screen out the effect of a contemporaneous shock on both $y_{i}$ and $m_{i j}$ is to use lagged GDP as an instrument for current GDP. ${ }^{25}$ The results, which exclude German trade due to a data problem, ${ }^{26}$ are presented in Table 8 . The first column is our usual specification, the second uses

${ }^{23}$ This is also a loose justification for allowing an intercept.

24 Results available on request.

25 More precisely, using data from World Development Indicators, we multiplied the figure for 1995 GDP in current local currency units by the ratio of the country's 1996 GDP deflator to its 1995 GDP deflator and converted that result to 1996 dollars using the official exchange rate.

${ }^{26}$ World Development Indicators does not include German GDP deflators. 
lagged GDP. The new parameter estimates are well within one standard error of the old and strengthen, if anything, the security and home bias effects.

\section{Conclusion}

Abundant evidence suggests that transactions costs associated with insecure exchange significantly impede international trade. Predation by thieves or by corrupt officials generates a price markup equivalent to a hidden tax or tariff. These price markups significantly constrain trade where legal systems poorly enforce commercial contracts and where economic policy lacks transparency and impartiality.

This paper builds a structural model of import demand in an insecure world and estimates the model using data collected by the World Economic Forum. We find that a 10\% rise in a country's index of transparency and impartiality leads to a $5 \%$ increase in its import volumes, other things equal. Costs associated with institutional weakness beg for serious consideration as we try to explain why countries trade so little.

We also find that the share of total expenditure devoted to traded goods declines as income per capita rises, other things equal. This result stands in contrast to recent papers which fail to reject homotheticity and calls into question the frequent use of homothetic preferences in trade models.

Finally, the paper suggests an explanation for the stylized fact that highincome, capital-abundant countries trade disproportionately with each other. These countries also enjoy strong institutions for the support of trade. Since the traded goods price markup depends on the degree of insecurity in the exporting and the importing countries, trade among the rich countries will be relatively unhampered by security-related transactions costs, while trade among poor countries will be doubly disadvantaged. 


\section{Appendix A: Modeling the Security of Trade}

This Appendix provides a multicountry generalization of the predation model found in Anderson and Marcouiller (1998). It illustrates the logic underlying Equation 1.2. The contract enforcement model of Anderson and Young (1999) provides an alternative route to the conclusion that insecurity leads to a markup in price.

In our model, thieves congregate at borders. We think of these borders as international boundaries, but they could also be the perimeters of the markets in which physical exchange takes place, as argued below. A complete transaction involves crossing two borders: the exporter must get the good out of his country and the importer must also evade predation when bringing the good into hers (alternatively, the seller must get the good into the marketplace and the buyer must get it out again). Any shipment which is defended by less than the usual and customary measures is identifiable as easy prey, attacked, and lost. Under these conditions, all shippers will take the normal defensive measures and thieves will attack randomly.

The probability that an exporter of good $j$ will successfully negotiate the border of his own country is given by an asymmetric contest success function: (A.1) $\pi_{j}=\frac{1}{1+\theta \frac{L_{j}{ }^{B}}{L_{j}{ }^{D}}}$,

a function of the supply of bandits along $j^{\prime}$ s border $L_{j}{ }^{B}$, the resources devoted to defending shipments at the border $L_{j}{ }^{D}$, and an exogenous technological parameter $\theta .{ }^{27}$ The ability to diversify risk makes $(1-\pi)$ equivalent, from the shippers' point of view, to a proportional insecurity tax on the value of every shipment. This tax is bounded on the unit interval, increasing in bandit labor and decreasing in defensive resources.

Anderson and Marcouiller (1998) fully endogenize the allocation of labor to defense in a two-country model. In this paper we treat defensive 
arrangements $L_{j}^{D}$ as given, for the sake of tractability in a multi-country model. We also assume the world's total supply of thieves to be exogenous: $L^{B}=\sum_{j} L_{j}^{B}$. However, each bandit is free to choose the location - the particular border - at which to attack shipments. (Admittedly, this story may fit the pirates and hijackers better than it fits corrupt customs officials, who cannot easily relocate across countries.) The endogenous allocation of bandits to different borders then determines $\pi_{j}$.

Bandits maximize expected loot $\sum_{j}\left(1-\pi_{j}\left(L_{j}^{B}, L_{j}^{D}, \theta\right)\right) v_{j}$, where $v_{j}$ is the volume of trade flowing through the border of country $j$. The reasonable assumption that uncoordinated bandits take trade volumes as given greatly simplifies this problem. Solving the first order conditions gives the allocation of bandit labor to each border:

$$
L_{j}^{B}=\frac{\pi_{j}\left(1-\pi_{j}\right) v_{j}}{\sum_{j} \pi_{j}\left(1-\pi_{j}\right) v_{j}} L^{B} .
$$

A bit of algebra produces the reduced form solution for $\pi_{j}$ :

$$
\pi_{j}=\left[\frac{L_{j}^{D}}{v_{j}}\right]^{1 / 2} \frac{\sum_{j} w_{j}\left(L_{j}^{D} / v_{j}\right)^{1 / 2}}{\frac{\theta L^{B}}{\sum_{j} v_{j}}+\sum_{j} w_{j}\left(L_{j}^{D} / v_{j}\right)}
$$

where $w_{j}$ is country $j^{\prime}$ s share of total world trade. Let $S_{j}^{*} \equiv\left(L_{j}^{D} / v_{j}\right)^{1 / 2}$ denote the strength of a country's institutions for the defense of trade. Then: (A.4) $\pi_{j}=S_{j}^{*} Z$, where $\mathrm{Z}$ is simply the constant term on the right in Equation A.3. We proxy $S^{*}$ with a loglinear function of observable characteristics $S$.

The relationship between trade and the price markup due to insecurity is as follows. For simplicity we disregard other sources of transactions cost. The probability of success on $j^{\prime}$ s sales to $i$ is $\pi_{i j}$. Risk neutral traders will arbitrage

${ }^{27}$ The same function has been used in the context of non-anonymous predation 
until $\pi_{i j} p_{i j}=p_{j}=1$, where the exporter's price is set equal to one by choice of units. We deal in the text with relative imports and relative prices. We assume that for both $i$ 's and $k^{\prime}$ s trade with $j$, the effect of insecurity at $j$ 's border is the same (i.e., the risks are independent), so the effect of $j$ 's border on relative probabilities and prices cancels. Thus $p_{i j} / p_{k j}=\pi_{k} / \pi_{i}=\left(S_{i} / S_{k}\right)^{\delta}$ using (A.4) and the proxy $S$ (treated as a scalar). This is the story underlying the incorporation of institutional quality indicators into Equation 1.2.

Now consider the potential effect of insecurity on domestic transactions. Our model generalizes from predation on international trade to predation on any trade. Consider a world in which goods are purchased by specialized brokers or traders at the factory door, then taken to a centralized market. Exchange takes place in the market, and then another shipper takes the goods to the final consumer. As long as trade routes are identified with different market portals, the insecurity markup will be determined as above. Thieves allocate themselves across portals to maximize expected loot, different routes are defended with different resources, and the probability of success is determined as above.

The exportable good is also sold at home. With insecurity the export has a domestic price $p_{i i}$ to consumers which differs from unity. The effect of insecurity on the price index of traded goods acts through the domestically produced traded good exactly as it does through traded goods imported from abroad, so no alteration is needed in the model of the text.

Domestic transactions in the non-tradable "home" good are affected by insecurity in a more complex way. We show that the traded goods expenditure share must be modified to:

$$
\phi_{i}=\phi\left(Y_{i}, N_{i}, P_{i}, S_{i}\right) .
$$

Assume home market insecurity is solely in the final goods market, since a full model of domestic insecurity would include intermediate goods and primary factor markets as well, taking us far beyond the paper's scope. The producer's price of the non-tradable good is $h$ while the consumer's price is $h / \pi$. Let $e(h / \pi, P, u)$ be the expenditure function of the representative agent and let

by Grossman and Kim (1995). 
$g(h, 1, v)$ be the gross domestic product function. Here, the price index of traded goods facing consumers is $P$ while the vector of factor endowments is $v$. Equilibrium is defined by the values of utility and home goods price consistent with balanced trade and home market clearance:

$\{U(P, \pi, v), H(P, \pi, v)\}=\left\{u, h \mid e(h / \pi, P, u)-g(h, 1, v)=0, e_{h}(h / \pi, P, u)-g_{h}(h, 1, v)=0\right\}$.

We use Shephard's and Hotelling's lemmas in defining market clearance. The reduced form traded goods expenditure share is defined as

$$
\phi(P, \pi, v) \equiv 1-H(P, \pi, v) e_{h}[H(P, \pi, v), P, U(P, \pi, v)] / e[\cdot] .
$$

Finally, replace $\pi$ with the proxy $S$ and replace $v$ with $(Y, N)$. Imposing loglinearity, essentially the same regression model emerges. The difference is that the effect of insecurity on trade now includes its effect directly on the reduced form trade expenditure share, not just its effect via the price index.

The interpretation of our results in the text is not much affected by this extension to domestic insecurity. The reduced form trade expenditure share is lowered by insecurity insofar as it raises $P$, the price index of tradable goods, and is raised by insecurity insofar as it raises $h / \pi$, the consumer price of the non-traded "home" good. Our results show that trade-reducing effects predominate. 


\section{References}

Anderson, James E. (1979), "A Theoretical Foundation for the Gravity Equation," American Economic Review 69:1, March, pp. 106-116.

Anderson, James E., and Douglas Marcouiller (1998), "Trade and Security, I: Anarchy," National Bureau of Economic Research Working Paper 6223.

Anderson, James E. and Leslie Young, (1999), “Trade and Contract Enforcement", Boston College.

Baier, Scott L. and Jeffrey Bergstrand (1999), "The Growth of World Trade; Tariffs, Transport Costs, and Income Similarity," working paper, September.

Bergstrand, Jeffrey H. (1985), "The Gravity Equation in International Trade: Some Microeconomic Foundations and Empirical Evidence," Review of Economics and Statistics 67:3, August, pp. 474-81.

Bergstrand, Jeffrey H. (1989), " The Generalized Gravity Equation, Monopolistic Competition, and the Factor-Proportions Theory in International Trade," Review of Economics and Statistics 71:1, February, pp. 143-53.

Brunetti, Aymo, Gregory Kisunko, and Beatrice Weder (1997), "Institutional Obstacles to Doing Business: Region-by-Region Results from a Worldwide Survey of the Private Sector," World Bank Policy Research Working Paper 1759.

Casella, Alessandra and James Rauch (1998), “Overcoming Informational Barriers to International Resource Allocation," NBER Working Paper No. 6627, June.

Davis, Donald, and David Weinstein (1998), "An Account of Global Factor Trade," NBER Working Paper No. 6785, November.

Davis, Donald, David Weinstein, Scott Bradford and Kazushige Shimpo, (1997), "Using International and Japanese Regional Data to Determine When the Factor Abundance Theory of Trade Works," American Economic Review 87:3, June, pp. 421-446.

Deardorff, Alan (1998), "Determinants of Bilateral Trade: Does Gravity Work in a Neoclassical World?" in Jeffrey A. Frankel, ed., The Regionalization of the World Economy, Chicago: University of Chicago for the NBER.

Feenstra, Robert, James Markusen and Andrew Rose (1999), "Using the Gravity Equation to Differentiate Among Alternative Theories of Trade," mimeo, August 3, 1999.

Fitzpatrick, Gary, and Marilyn Modlin (1986), Direct-Line Distances: International Edition, Metuchen and London: Scarecrow Press.

Frankel, Jeffrey, Ernesto Stein and Shang-jin Wei (1998), "Continental Trading Blocs: Are They Natural or Supernatural?" in Jeffrey A. Frankel, ed., The Regionalization of the World Economy, Chicago: University of Chicago for the NBER.

Gould, David M. (1994), "Immigrant Links to the Home Country: Empirical Implications for U.S. Bilateral Trade Flows," Review of Economics and Statistics 76:2, May, pp.302-316.

Grossman, Gene (1998), "Comment," in Jeffrey A. Frankel, ed., The Regionalization of the World Economy, Chicago: University of Chicago for the NBER.

Grossman, Herschel, and Minseong Kim (1995), "Swords or Plowshares: A 
Theory of the Security of Claims to Property," Journal of Political Economy 103, pp. 1275-1288

Helliwell, John F. (1998), How Much Do National Borders Matter?. Washington: Brookings Institution Press.

Hummels, David (1999), “Toward a Geography of Trade Costs," mimeo, University of Chicago.

Hunter, Linda, and James Markusen (1988), "Per-Capita Income As a Determinant of Trade," in Robert C. Feenstra, ed., Empirical Methods for International Trade, Cambridge: The MIT Press, pp.89-109.

Marcouiller, Douglas, and Leslie Young (1995), "The Black Hole of Graft: The Predatory State and the Informal Economy," American Economic Review 85:3, June, pp.630-646.

Markusen, James R. (1986), “Explaining the Volume of Trade: An Eclectic Approach," American Economic Review 76:5, December, pp. 1002-1011.

McCallum, John (1995), "National Borders Matter: Canada-US Regional Trade Patterns", American Economic Review, 85:3, June, pp. 615-623.

Oguledo, Victor I. and Craig R. MacPhee (1994), “Gravity Models: A Reformulation and an Application to Discriminatory Trade Arrangements," Applied Economics 26, pp. 107-120.

Rauch, James E. (1999), "Networks Versus Markets in International Trade," Journal of International Economics 48, June, pp.7-35.

Rauch, James E. and Vitor Trindade (1999), "Ethnic Chinese Networks in International Trade," NBER Working Paper No. 7189, June.

Rodrik, Dani (2000), "How Far Will International Economic Integration Go?" The Journal of Economic Perspectives 14:1, Winter, pp.177-186.

Thursby, Jerry G. and Marie C. Thursby (1987), "Bilateral Trade Flows, the Linder Hypothesis, and Exchange Risk," Review of Economics and Statistics 69:3, August, pp. 488-495.

Trefler, Daniel (1995), "The Case of the Missing Trade and Other Mysteries", American Economic Review, 85:5, December, pp. 1029-1046.

Wei, Shang-jin (1997), "Why is Corruption so Much More Taxing than Tax: Arbitrariness Kills," NBER Working Paper 6255, November 1997.

World Economic Forum (1997), The Global Competitiveness Report 1997 (Geneva: World Economic Forum). 
Figure 1. Transparency and Enforceability Scores

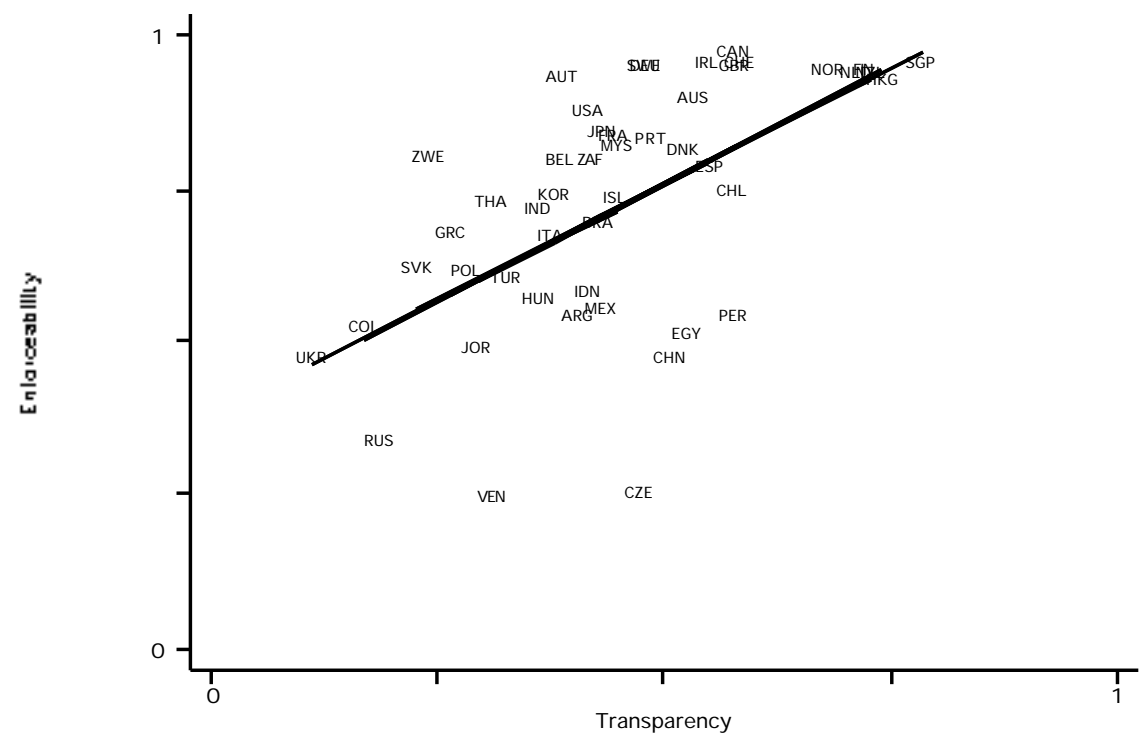




\section{Table 1. Rankings of "Obstacles for Doing Business"}

\begin{tabular}{lc}
\hline & $\begin{array}{c}\text { Worldwide } \\
\text { Sample }\end{array}$ \\
\hline Tax Regulations or High Taxes & 1 \\
Corruption & 2 \\
Financing & 3 \\
Inadequate Infrastructure & 4 \\
Crime and Theft & 5 \\
Inflation & 6 \\
Uncertainty of Cost of Regulations & 7 \\
Policy Instability & 8 \\
Labor Regulations & 9 \\
Regulations on Foreign Trade & 10 \\
Safety or Environmental Regulations & 11 \\
Start-up Regulations & 12 \\
Foreign Currency Regulations & 13 \\
Price Controls & 14 \\
Terrorism & 15 \\
\hline Source: Brunetti, Kisunk, and Weder, $1997,70.7$
\end{tabular}

Source: Brunetti, Kisunko, and Weder, 1997, p. 70. 
Table 2. Composite Security Scores

\begin{tabular}{lclcll}
\hline IMPORTER & Score & IMPORTER & Score & IMPORTER & Score \\
\hline Russia & -2.614 & Italy & -0.362 & France & 0.689 \\
Ukraine & -2.377 & Indonesia & -0.284 & Australia & 0.704 \\
Venezuela & -2.218 & India & -0.264 & Sweden & 0.779 \\
Colombia & -2.098 & Zimbabwe & -0.240 & Austria & 0.807 \\
Greece & -1.195 & Peru & -0.235 & Denmark & 0.857 \\
Poland & -0.858 & Korea & -0.217 & Ireland & 0.864 \\
Thailand & -0.796 & China & -0.184 & Germany & 0.931 \\
J ordan & -0.794 & Belgium-Luxembourg & 0.055 & New Zealand & 0.997 \\
Hungary & -0.791 & Egypt & 0.227 & United Kingdom & 1.034 \\
Mexico & -0.749 & Spain & 0.382 & Netherlands & 1.036 \\
South Africa & -0.602 & Portugal & 0.391 & Canada & 1.050 \\
Argentina & -0.579 & Iceland & 0.451 & China: Hong Kong & 1.134 \\
Turkey & -0.539 & Malaysia & 0.499 & Norway & 1.142 \\
Slovak Republic & -0.524 & Japan & 0.562 & Switzerland & 1.159 \\
Brazil & -0.521 & United States & 0.651 & Finland & 1.173 \\
Czech Republic & -0.452 & Chile & 0.680 & Singapore & 1.241 \\
\hline
\end{tabular}


Table 3. Importers in the Data Set

\begin{tabular}{lclclc}
\hline IMPORTER & Obs. & IMPORTER & Obs. & IMPORTER & Obs. \\
\hline Argentina & 46 & Hungary & 47 & Russia & 47 \\
Australia & 47 & Iceland & 42 & Singapore & 44 \\
Austria & 46 & India & 47 & Slovak Republic & 47 \\
Belgium-Luxembourg & 47 & Indonesia & 46 & South Africa & 47 \\
Brazil & 47 & Ireland & 47 & Spain & 47 \\
Canada & 47 & Italy & 47 & Sweden & 47 \\
Chile & 36 & Japan & 47 & Switzerland & 46 \\
China & 47 & J ordan & 42 & Thailand & 43 \\
China: Hong Kong & 47 & Korea & 33 & Turkey & 47 \\
Colombia & 46 & Malaysia & 46 & Ukraine & 41 \\
Czech Republic & 47 & Mexico & 38 & United Kingdom & 47 \\
Denmark & 47 & Netherlands & 47 & United States & 47 \\
Egypt & 47 & New Zealand & 47 & Venezuela & 45 \\
Finland & 47 & Norway & 46 & Zimbabwe & 42 \\
France & 47 & Peru & 45 & & \\
Germany & 47 & Poland & 47 & & 2182 \\
Greece & 46 & Portugal & 47 & Total & \\
\hline
\end{tabular}


Table 4. Ratios with USA as Base Country

\begin{tabular}{lccc}
\hline Ratio: USA as Base & Number Observations & Mean & Standard Deviation \\
\hline Import Ratio cif & 2135 & 0.281 & 0.977 \\
GDP Ratio & 2135 & 0.079 & 0.173 \\
GDP Per Capita Ratio & 2135 & 0.520 & 0.441 \\
Transparency Ratio & 2135 & 1.085 & 0.370 \\
Enforceability Ratio & 2135 & 0.833 & 0.226 \\
Composite Security Ratio & 2135 & 0.012 & 0.981 \\
Common Border Ratio & 2135 & 1.026 & 0.238 \\
Common Language Ratio & 2135 & 0.948 & 0.263 \\
Distance Ratio & 2135 & 1.204 & 1.848 \\
Tariff Ratio & 2135 & 1.035 & 0.068 \\
\hline
\end{tabular}


Table 5. Relative Import Demand, USA as the Base

\begin{tabular}{lcccccc}
\hline Variable & Reg 1 & Reg 2 & Reg 3 & Reg 4 & Tobit 1 & Tobit 2 \\
\hline Log GDP Ratio & 0.837 & 0.855 & 0.860 & 0.866 & 0.907 & 0.911 \\
& $(0.045)$ & $(0.042)$ & $(0.037)$ & $(0.038)$ & $(0.037)$ & $(0.040)$ \\
Log GDP Per Capita Ratio & 0.141 & 0.018 & -0.206 & -0.191 & -0.244 & -0.215 \\
& $(0.058)$ & $(0.094)$ & $(0.105)$ & $(0.122)$ & $(0.108)$ & $(0.125)$ \\
Log Transparency Ratio &. &. & 0.530 &. & 0.620 &. \\
&. &. & $(0.169)$ &. & $(0.173)$ &. \\
Log Enforceability Ratio &. &. & 0.385 &. & 0.307 &. \\
Relative Composite Security &. &. & $(0.199)$ &. & $(0.196)$ &. \\
&. &. &. & 0.285 &. & 0.279 \\
Log Common Border Ratio & 0.908 & 0.794 & 0.753 & 0.747 & 0.668 & 0.665 \\
& $(0.140)$ & $(0.155)$ & $(0.160)$ & $(0.163)$ & $(0.184)$ & $(0.186)$ \\
Log Common Language Ratio & 0.314 & 0.327 & 0.331 & 0.336 & 0.349 & 0.358 \\
& $(0.081)$ & $(0.080)$ & $(0.082)$ & $(0.082)$ & $(0.109)$ & $(0.109)$ \\
Log Distance Ratio & -1.134 & -1.109 & -1.097 & -1.095 & -1.134 & -1.133 \\
Log Adjusted Tariff Ratio & $(0.054)$ & $(0.058)$ & $(0.056)$ & $(0.056)$ & $(0.055)$ & $(0.056)$ \\
&. & -2.973 & -4.753 & -4.814 & -4.773 & -4.699 \\
Weighted Log Border Ratio & -1.807 & $(1.992)$ & $(2.146)$ & $(2.343)$ & $(2.126)$ & $(2.327)$ \\
& $(1.474)$ & $(1.654$ & -1.092 & -1.391 & -0.934 & -1.169 \\
Weighted Log Language Ratio & 1.390 & 1.438 & $(1.332)$ & $(1.364)$ & $(1.363)$ & $(1.426)$ \\
& $(1.639)$ & $(1.486)$ & $(1.448)$ & $(1.363)$ & $(1.417)$ & $(1.433)$ \\
Weighted Log Distance Ratio & 0.420 & 0.424 & 0.382 & 0.451 & 0.300 & 0.386 \\
Constant & $(0.164)$ & $(0.160)$ & $(0.137)$ & $(0.130)$ & $(0.126)$ & $(0.129)$ \\
Number Observations & 0.055 & 0.076 & -0.169 & -0.184 & -0.142 & -0.131 \\
R-squared & $(0.158)$ & $(0.146)$ & $(0.135)$ & $(0.147)$ & $(0.121)$ & $(0.144)$ \\
Log Likelihood & 2135 & 2135 & 2135 & 2135 & 2159 & 2159 \\
\hline Robut standard & .69 & .69 & .70 & .70 & & \\
& & & & & -3859 & -3865 \\
\hline
\end{tabular}

Robust standard error (Huber/White) with clustering by importer given in parentheses.

Imports are cif, as reported by DOTS. Results using interpolated fob figures are available on request. 
Table 6. Maximum Likelihood Parameter Estimates Constrained Model (Equation 1.8)

\begin{tabular}{ccc}
\hline Parameter & Model 1 & Model 2 \\
\hline$\gamma_{1}+1$ & 0.854 & 0.859 \\
& $(0.036)$ & $(0.037)$ \\
$\gamma_{2}$ & -0.211 & -0.194 \\
$\gamma_{3}-1$ & $(0.107)$ & $(0.122)$ \\
& -4.801 & -4.850 \\
$\delta_{1 a}$ & $(2.193)$ & $(2.381)$ \\
& -0.110 &. \\
$\delta_{1 b}$ & $(0.037)$ &. \\
& -0.084 &. \\
$\delta_{1}$ & $(0.053)$ & - \\
$\delta_{2}$ &. & -0.059 \\
& $-.0 .020)$ \\
$\delta_{3}$ & -0.094 & -0.082 \\
& $(0.058)$ & $(0.055)$ \\
$\delta_{4}$ & -0.042 & -0.037 \\
& $(0.024)$ & $(0.023)$ \\
$\sigma$ & 0.139 & 0.120 \\
& $(0.068)$ & $(0.066)$ \\
Constant & 7.915 & 9.125 \\
& $(3.815)$ & $(4.962)$ \\
Observations & -0.194 & -0.211 \\
Log Likelihood & $(0.127)$ & $(0.136)$ \\
Model 1 includes the transparency and enforceability indexes. & 2135 \\
Model 2 substitutes the composite security factor. Huber/White \\
robust standard errors with clustering by importer in parentheses.
\end{tabular}


Table 7. Coefficients on Security Variables, All US Trade Excluded

\begin{tabular}{lcccc}
\hline Variable & Brazil Base & China Base & Brazil Base & China Base \\
\hline Log Transparency Ratio & 0.56 & 0.52 &. &. \\
& $(.16)$ & $(.17)$ &. &. \\
Log Enforceability Ratio & 0.46 & 0.46 &. &. \\
& $(.20)$ & $(.20)$ &. &. \\
Relative Composite Security &. &. & 0.30 & 0.29 \\
&. &. & $.07)$ & $(.07)$ \\
Number Observations & 2042 & 2042 & 2042 & 2042 \\
R-squared & .72 & .60 & .72 & .59 \\
\hline
\end{tabular}

The full set of independent variables used in Table 5 was used again here; only these coefficients are reported. Robust standard errors with clustering by importer in parentheses. 
Table 8. Relative Import Demand, USA as the Base, Lagged GDP

\begin{tabular}{|c|c|c|c|c|}
\hline Variable & Base & $\begin{array}{l}\text { Lagged } \\
\text { GDP }\end{array}$ & Base & $\begin{array}{c}\text { Lagged } \\
\text { GDP }\end{array}$ \\
\hline Log GDP Ratio & $\begin{array}{l}0.859 \\
(0.04)\end{array}$ & . & $\begin{array}{l}0.866 \\
(0.04)\end{array}$ & . \\
\hline Log Instrumented GDP Ratio & . & $\begin{array}{l}0.855 \\
(0.04)\end{array}$ & . & $\begin{array}{l}0.863 \\
(0.04)\end{array}$ \\
\hline Log Per Capita GDP Ratio & $\begin{array}{l}-0.202 \\
(0.11)\end{array}$ & . & $\begin{array}{l}-0.188 \\
(0.12)\end{array}$ & . \\
\hline Log Instrumented Per Capita GDP Ratio & . & $\begin{array}{r}-0.225 \\
(0.11)\end{array}$ & . & $\begin{array}{l}-0.211 \\
(0.12)\end{array}$ \\
\hline Log Transparency Ratio & $\begin{array}{l}0.538 \\
(0.17)\end{array}$ & $\begin{array}{c}0.578 \\
(0.17)\end{array}$ & . & . \\
\hline Log Enforceability Ratio & $\begin{array}{l}0.370 \\
(0.20)\end{array}$ & $\begin{array}{l}0.411 \\
(0.21)\end{array}$ & . & . \\
\hline Composite Security Factor & . & . & $\begin{array}{l}0.286 \\
(0.07)\end{array}$ & $\begin{array}{l}0.312 \\
(0.07)\end{array}$ \\
\hline Log Adjacency Ratio & $\begin{array}{l}0.800 \\
(0.17)\end{array}$ & $\begin{array}{l}0.791 \\
(0.17)\end{array}$ & $\begin{array}{l}0.795 \\
(0.18)\end{array}$ & $\begin{array}{l}0.786 \\
(0.18)\end{array}$ \\
\hline Log Common Language Ratio & $\begin{array}{l}0.338 \\
(0.08)\end{array}$ & $\begin{array}{l}0.339 \\
(0.08)\end{array}$ & $\begin{array}{l}0.344 \\
(0.08)\end{array}$ & $\begin{array}{l}0.346 \\
(0.08)\end{array}$ \\
\hline Log Distance Ratio & $\begin{array}{l}-1.102 \\
(0.06)\end{array}$ & $\begin{array}{c}-1.101 \\
(0.06)\end{array}$ & $\begin{array}{l}-1.101 \\
(0.06)\end{array}$ & $\begin{array}{l}-1.100 \\
(0.06)\end{array}$ \\
\hline Log Tariff Ratio & $\begin{array}{l}-4.719 \\
(2.19)\end{array}$ & $\begin{array}{r}-4.881 \\
(2.22)\end{array}$ & $\begin{array}{c}-4.780 \\
(2.39)\end{array}$ & $\begin{array}{l}-4.956 \\
(2.42)\end{array}$ \\
\hline Weighted Log Adjacency & $\begin{array}{l}-1.188 \\
(1.42)\end{array}$ & $\begin{array}{c}-1.103 \\
(1.47)\end{array}$ & $\begin{array}{l}-1.419 \\
(1.45)\end{array}$ & $\begin{array}{l}-1.361 \\
(1.51)\end{array}$ \\
\hline Weighted Log Language & $\begin{array}{l}0.042 \\
(1.47)\end{array}$ & $\begin{array}{r}-0.086 \\
(1.48)\end{array}$ & $\begin{array}{c}-0.128 \\
(1.37)\end{array}$ & $\begin{array}{l}-0.268 \\
(1.39)\end{array}$ \\
\hline Weighted Log Distance & $\begin{array}{l}0.364 \\
(0.14)\end{array}$ & $\begin{array}{l}0.369 \\
(0.14)\end{array}$ & $\begin{array}{l}0.437 \\
(0.13)\end{array}$ & $\begin{array}{l}0.448 \\
(0.13)\end{array}$ \\
\hline Constant & $\begin{array}{l}-0.185 \\
(0.14)\end{array}$ & $\begin{array}{c}-0.211 \\
(0.14)\end{array}$ & $\begin{array}{l}-0.195 \\
(0.15)\end{array}$ & $\begin{array}{l}-0.225 \\
(0.15)\end{array}$ \\
\hline Number Observations & 2042 & 2042 & 2042 & 2042 \\
\hline R-squared & .68 & .68 & .68 & .68 \\
\hline
\end{tabular}

Robust standard error in parentheses, with clustering by importer. 